\title{
Action de certains Champignons entomophages, cultivés sur les milieux appropriés attractifs, sur le Termite de Saintonge Reticulitermes santonensis (de Feytaud)
}

\author{
Par C. TOUMANOFF et J. ROMBAUT
}

Les expériences sur l'infection des Termites par les Champignons entomophages, comme nous l'avons indiqué dans un exposé d'ensemble, donnent d'excellents résultats, ceci par simple contact avec les cultures du Champignon, en milieu solide, ainsi que par le séjour des Insectes sur un mélange de Champignons en culture liquide et de sciure de bois.

Toutefois, il est intéressant de procéder à l'infection de ces Insectes en leur fournissant, en nourriture, ces Champignons avec de la cellulose, pour laquelle, on le sait, ils ont une prédilection spéciale.

Les essais préliminaires (Toumanoff) ont permis de conclure que l'addition à la sciure d'une culture de Champignons et d'une certaine quantité de cellulose est particulièrement favorable à l'infection des Termites (*).

Toutefois, pour produire une action plus efficace, il nous a paru intéressant de cultiver les Champignons en présence de cellulose et d'essayer leur effet sur les Termites.

Afin de posséder, pour l'expérimentation, une production en quantité suffisante de spores et de mycélium fixé sur la cellulose, le recours au procédé industriel s'est avéré indispensable.

Voici l'exposé du procédé industriel qui aboutit à la production de l'insecticide biologique et dont l'effet a été essayé, comme on le verra, aux diverses phases de la fabrication.

Le procédé pour obtenir ces préparations consiste à cultiver, en milieu nutritif agité et aéré, des Champignons appartenant aux espèces des groupes Metarrhizium et Beauveria.

(*) On trouvera les indications bibliographiques sur le sujet dans la publication de C. Toumanoff: Action des divers champignons etc... dans ce numéro d'Annales. 
Les milieux nutritifs et les conditions de culture ont été établis pour produire une concentration élevée de spores.

Les suspensions de spores ainsi obtenues, après empâtage à l'aide de diverses matières à base de cellulose, sont séchées sous vide, dans des conditions assurant la viabilité des spores ainsi traitées.

\section{A) Conditions de fermentation}

Les souches de Champignons entomophages des espèces déjà nommées sont cultivées sur gélose inclinée de Sabouraud, pendant huit jours, à $28^{\circ} \mathrm{C}$. Ces tubes de gélose servent ensuite à ensemencer des milieux liquides répartis en fioles de type Fernbach.

Ces milieux ont la composition suivante :

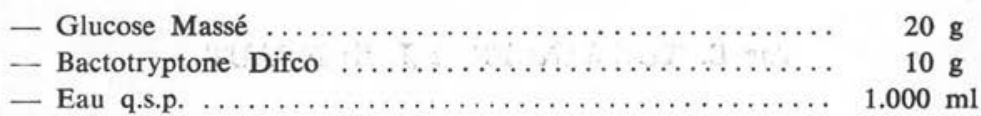

Après ensemencement, les fioles sont agitées pendant 72 heures à $28^{\circ} \mathrm{C}$, selon un mouvement rotatif de $210 \mathrm{t} / \mathrm{m}$.

Deux litres de ces précultures, obtenues dans les conditions décrites plus haut, sont utilisées pour ensemencer un appareil industriel de 300 litres agité mécaniquement et aéré, contenant le milieu de culture suivant :

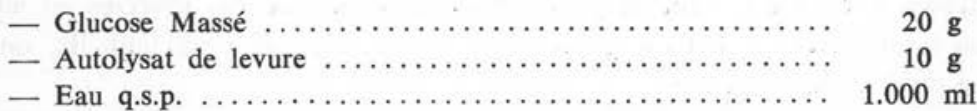

Les conditions de culture ont été ainsi établies :

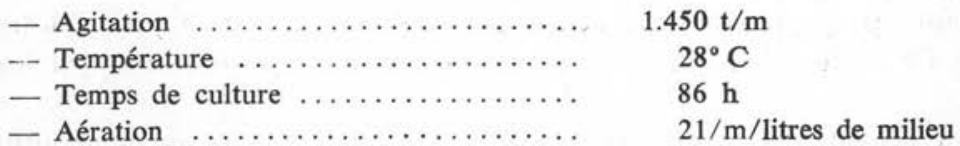

En fin de culture, la numération des spores donne une valeur d'environ $4 \times$ $10^{9}$ spores par $\mathrm{ml}$.

\section{B) Obtention du mélange insecticide}

$6 \mathrm{~kg}$ de cellulose en poudre, ou $3 \mathrm{~kg}$ de sciure de bois de sapin, sont mélangés aux 300 litres de milieu de culture, obtenus après fermentation. Après brassage, le mélange est essoré sur essoreuse-centrifuge et séché en étuve sous vide sur plateaux pendant 48 heures à $40^{\circ} \mathrm{C}$. Après le séchage, un broyage permet d'obtenir une poudre homogène contenant environ $3 \times 10^{7}$ spores $/ \mathrm{g}$. 
Nos essais, effectués tout d'abord avec « le produit brut », c'est-à-dire le mycélium fixé sur la cellulose, se présente sous forme d'une masse compacte et dure, difficile à écraser. Cette masse résulte de la première phase de la fabrication de l'insecticide fongique.

Nous avons déposé ce produit dans des boîtes de Pétri contenant de la sciure.

D'autre part, nous avons utilisé le mycélium et les spores fixés sur la sciure selon le procédé indiqué plus haut. Il s'agissait dans les deux cas du pré-produit avant son broyage.

Dans les deux cas le nombre des spores fut de $4 \times 10^{9}$ par ml.

Nous relaterons dans les lignes qui suivent les expériences concernant l'infection des termites par le mycélium et les spores récoltés sur la cellulose, nous relaterons ensuite quelques essais avec le mycélium fixé sur la sciure.

\section{Contamination des Termites par le mycélium et les spores récoltées sur la cellulose}

Des expériences ont été faites dans ce sens avec divers Champignons et notamment : Metarrhizium anisopliae (Metch) Sorokin (souche de Hollande), Beauveria bassiana (Balsamo) Vuill. (souche de Hollande), Beauveria bassiana (Balsamo) Vuill. (souche de Tchécoslovaquie).

Sur ce plan, deux séries d'expériences ont été réalisées simultanément et voici de quelle manière.

$1^{\circ}$ Dans des boîtes de Pétri ont été placés des morceaux de mycélium récoltés sur la cellulose (mycélium + spores). Dans les mêmes boîtes ont été introduits des petits tas de sciure de bois humectés, sans contact avec la masse cellulosique infectante.

$2^{\circ}$ Une autre série d'expériences consistait à mélanger le mycélium et la sciure humectée.

Nous relaterons tout d'abord les résultats d'une série d'expériences réalisées selon le premier procédé.

1) Les résultats ont été les suivants : l'action de Metarrhizium anisopliae sur les Termites commençait à se manifester au bout de 72 heures par une mortalité de $15 \%$; les $4^{\circ}$ et $5^{\circ}$ jour $35 \%$ d'Insectes ont été trouvés morts, et enfin, le $9^{\mathrm{e}}$ jour, encore $15 \%$ des Termites moururent; la mortalité totale des lots en expériences fut observée le $16^{\circ}$ jour.

En ce qui concerne Beauveria bassiana, les résultats obtenus dans les mêmes conditions ont été plus spectaculaires. En effet, la mortalité fut de $20 \%$ avec la souche de Hollande et de $10 \%$ avec la seconde souche au bout de quarante-huit heures. Avec la souche de Hollande, $75 \%$ d'Insectes mourraient le $15^{\circ}$ jour et $100 \%$ le $16^{\circ}$, ceci en ce qui concerne la même espèce de Beauveria.

Ces essais avaient pour but de voir si le mycélium fixé sur la cellulose exerçait un effet attractif sur les Termites. Nous avons constaté avec Metarrhizium anisopliae qu'au 
début de ces expériences les Termites manifestaient une tendance à rester tout d'abord sur le conglomérat du mycélium, puis, fuyant la lumière, venaient s'installer dans la sciure où ils creusèrent leurs galeries dans lesquelles ils finissaient par mourir.

En ce qui concerne le produit brut à base de Beauveria, les Insectes se plaçaient aussi bien dans la sciure que sur le tas constitué par le mélange mycélium et spores.

Il résulte de ces expériences, qu'il serait fastidieux de citer et qui en général portaient sur 20 Insectes placés dans des boîtes de Pétri de $10 \times 10 \mathrm{~cm}$, que, malgré la séparation du produit et de la sciure, la mortalité fut totale.

Cette mortalité s'échelonnait cependant sur une période assez longue, mais démontrait aussi que les Termites ne se contentaient pas de s'attaquer à la sciure, mais entraient en contact avec les tas infectants qui les attiraient.

Une autre série d'essais fut faite avec le mycélium et les spores récoltées sur la cellulose, mélangés à une quantité à peu près égale de sciure.

2) Dans ces conditions, le contact de l'Insecte avec le matériel de contamination était plus étroit et cela a exercé un effet appréciable sur la rapidité de l'infection et de la mortalité.

C'est ainsi que les Termites mis en présence de Metarrhizium anisopliae devenaient partiellement malades (de 5 à $10 \%$ ) au bout de quarante-huit heures et une mortalité de $85 \%$ s'observait soixante-douze heures après le commencement des expériences.

Il en fut à peu près de même en ce qui concerne les souches Beauveria bassiana de Hollande et de Tchécoslovaquie.

La mortalité de tous les Insectes $(100 \%)$ se produisit au bout de cinq-six jours Jans la plupart des essais.

Avec la souche de Hollande, le même effet se produisit au bout de six jours.

\section{Contamination par la poudre fongique}

Nous avons relaté plus haut les diverses phases de culture des Champignons entomophages, culture qui aboutit à l'obtention d'une poudre homogène contenant environ $3 \times 10^{7}$ spores $/ \mathrm{g}$.

Cette poudre fut également essayée en laboratoire ; les essais étaient faits avec la poudre mélangée avec de la sciure de bois de pin fraîche, dans la proportion de $7 \mathrm{~g}$ de sciure pour $3 \mathrm{~g}$ de poudre.

Les Insectes soumis à l'expérience manifestaient les signes de la maladie au bout de quarante-huit heures et $100 \%$ des Termites mouraient au bout de quatre jours.

Les résultats étaient donc plus rapides qu'avec le précédent produit.

L'avantage d'utilisation de cette poudre est, qu'en milieu humidifié et avec de la sciure, elle donne lieu à la croissance des Champignons.

C'est ainsi que les contenus des boîtes de Pétri dans lesquelles ont été effectuées les contaminations des Termites étaient envahis par le mycélium, puis par les appareils de fructification de Metarrhizium et de Beauveria. Dans les premiers cas, au bout de quelques jours, on observait un enduit vert, dans le second, un enduit blanc uniforme. 
L'examen microscopique permettait d'y voir les appareils de fructification caractéristiques pour chaque espèce.

Les Termites en expériences, placés dans les boîtes de Pétri avec la sciure et la poudre fongique, étaient, au bout de qtiarante-huit heures, littéralement enrobés dans le mycélium et transformés en momies 'sn forme de tonnelets.

L'efficacité de la poudre fongique sur le Termite dans les conditions de laboratoire nous a incité à l'expérimentation de son effet dans la nature. Les résultats en seront relatés dans une publication ultérieu:e.

\section{Résumé et Conclusion}

De l'ensemble des fais exposés, il résulte que deux Champignons entomophages, Beauveria bassiana et Metarrhizium anisopliae, peuvent, dans des conditions appropriées et par un procédé spécial de culture, être fixés, soit sur la sciure de bois, soit sur la poudre de cellulose.

Les conglomérats séchés de ces cultures, composées de mycélium + spore + cellulose, ou bien de mycélium + spore + sciure, s'avèrent capables de provoquer l'infection des Termites.

Cette infection est plutôt lente lorsqu'on tient le produit infectieux plus ou moins éloigné des Termites, mais l'action pathogène est néanmoins manifeste, ce qui dénote une attraction des Insectes pour le pré-produit.

C'est cependant une poudre fongique fabriquée à partir de cultures de ces Champignons, poudre contenant de la ce.lulose, aui s'avère extrêmement infectieuse pour les Termites, et qui offre expérimenta'ement la possibilité de son extension dans la nature ce qui incite à son emploi sur le terrain.

(Institut Pasteur de Paris, 25, rue du Docteur-Roux, Paris, $15^{\circ}$ ). 